\title{
Pentigraf sebagai inovasi pembelajaran sejarah pada masyarakat era disrupsi
}

\author{
Ardi Wina Saputra ${ }^{2, I_{1},}$, Priska Meilasari ${ }^{2,2}$ \\ ${ }_{2}^{2}$ Pendidikan Bahasa Indonesia, Fakultas Ilmu Pendidikan, Universitas Katolik Widya Mandala Madiun, J1. Manggis No I5, \\ Madiun, Indonesia \\ a,2 Sastra Inggris, Fakultas Sastra, Universitas Katolik Widya Mandala Madiun, J1. Manggis No I5, Madiun, Indonesia \\ 1'c.ardi_7@yahoo.com; ${ }^{2}$ meillasaripriska@gmail.com \\ *Corresponding author: c.ardi_7@yahoo.com
}

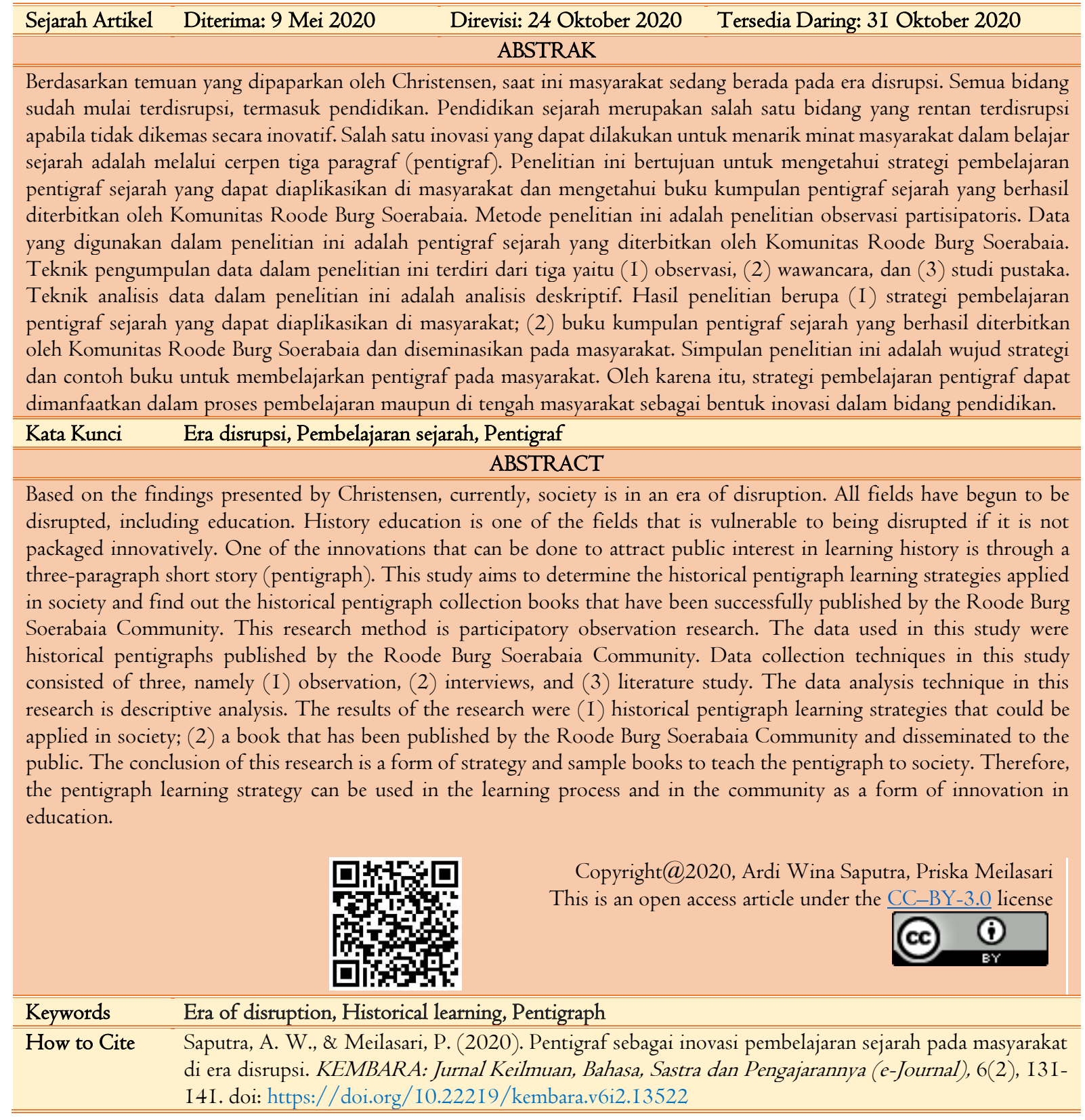

\section{PENDAHULUAN}

Perkembangan teknologi informasi dan komunikasi yang melesat cepat dalam satu dekade terakhir mengakibatkan perubahan di segala sendi kehidupan. Profesor administrasi bisnis dari Harvard Busines School, Clay M. Christensen (Andarwati, 2019) mengatakan bahwa saat ini masyarakat sedang 
berada dalam era disrupsi. Teknologi informasi dan komunikasi memegang peran besar dalam era ini (Helaluddin, Tulak, \& Rante, 2019; Rahayu, 2019). Menurut Saryono (2018), era disrupsi memiliki tiga ciri utama yaitu (I) ditopang internet, kecerdasan buatan, dan maha data, (2) berlangsung tak terduga dan taksa, dan (3) berlangsung cepat dan tak kasat mata. Disrupsi sudah merambah ke segala aspek kehidupan, termasuk pendidikan, salah satu dampaknya adalah munculnya model pendidikan 4.0 (Maskurin, 2019; Purnomo, Ratnawati, \& Aristin, 2017). Model pendidikan yang berubah tentu berpengaruh pada proses pembelajaran yang dilakukan. Berubahnya proses pembelajaran juga disesuaikan dengan kompetensi dasar pembelajar (Kristiawan \& Rahmat, 20I8; I. R. Lubis \& Ikhsan, 2015). Saat ini pembelajar yang mengenyam jalur pendidikan baik formal atau non formal telah didominasi oleh generasi Z (Yemima \& Stefani, 2019).

Kemajuan teknologi informasi dan komunikasi yang semakin marak membuat pembelajar zaman sekarang tergolong sebagai anak-anak yang hidup dalam generasi Z. Menurut Tapscott and Barry (2009), anak-anak yang disebut generasi Z dilahirkan di era 1998 hingga tahun 2009, anak-anak ini juga disebut sebagai anak-anak teknologi (Ishak, Omar, Al Bakri, \& Osman, 2018; A. H. Lubis \& Dasopang, 2020). Mereka disebut generasi $Z$ karena saat mereka lahir, teknologi informasi dan komunikasi sedang berkembang dengan sangat cepat (Andarwati, 2019; Faqihuddin, 2017), televisi, handphone, hingga komputer sudah ada saat anak-anak tersebut lahir. Singh (20I4) menyatakan bahwa generasi Z memiliki musuh lebih banyak daripada generasi sebelumnya. Hal tersebut karena generasi $Z$ cenderung lebih individualistik (Faqihuddin, 2017). Oleh sebab itu, perlu pemahaman lebih untuk memahami generasi yang lahir di era 2000 atau generasi $Z$ ini.

Menanggapi fenomena generasi $Z$ ini, Kasali (2017) dengan tegas menyebut fenomena ini sebagai Strawberry Generation. Fenomena ini dinamakan Strawberry Generation karena secara imajiner wujudnya seperti stroberi yaitu indah, menawan, tapi mudah rapuh (Atencio, Tan, Ho, \& Ching, 20I5; Youarti \& Hidayah, 2018). Wujud yang indah tersebut karena hampir semua anak memiliki telepon pintar dan dalam telepon tersebut dilengkapi dengan akses untuk dapat menjangkau internet (Atencio et al., 2015). Faqihuddin (2017), menyampaikan empat karakteristik Generasi Z, pertama, fasih dalam teknologi sehingga membuatnya cepat menguasai gawai terbaru. Kedua, memiliki rasa kesadaran interaksi sosial yang tinggi. Ketiga, ekspresif terhadap segala sesuatu yang ditangkap oleh inderanya. Keempat, sangat dinamis sehingga sering berpindah dengan cepat dari satu tempat ke tempat lain. Kemunculan generasi $\mathrm{Z}$ berdampak pada proses pendidikan dan pembelajaran baik di sektor formal maupun non formal (Bakti \& Safitri, 2017; Maskurin, 2019). Materi pembelajaran yang dirasa membosankan harus dikemas sedemikian rupa agar menarik dan sesuai dengan kebutuhan pendidikan era 4.0 (Helaluddin et al., 2019).

Berdasarkan hasil observasi yang dilakukan peneliti, anggapan bahwa pembelajaran sejarah dianggap sebagai pembelajaran yang membosankan masih sering ditemui di masyarakat (Fachrudin, 2016). Hal tersebut karena orang cenderung menganggap bahwa pembelajaran sejarah adalah pembelajaran hafalan (Hardiana, 2017; Pradana, 2017). Nama tokoh, waktu terjadinya peristiwa, lokasi terjadinya peristiwa masih lebih diutamakan daripada peristiwa itu sendiri. Belajar sejarah seharusnya belajar peristiwa, memahami makna atau pesan dalam peristiwa dari satu kejadian ke kejadian lain (Permatasari, 20I4). Setiap peristiwa pasti memiliki nilai positif dan negatif, nilai positif tersebut lebih baik diteruskan, sedangkan nilai negatifnya ditinggalkan (Rahayu, 2019). Itulah hakekat belajar sejarah, memaknai suatu peristiwa bukan hanya sekedar menghafal (Hardiana, 2017). Berdasarkan hal tersebut, maka patut digaris bawahi bahwa belajar sejarah adalah belajar peristiwa. Semakin banyak peristiwa yang disajikan semakin banyak nilai hidup yang dapat dipahami. Salah satu cara yang dapat dilakukan untuk memaknai sebuah peristiwa adalah dengan menuliskannya kembali (Andarwati, 2019).

Bentuk penulisan peristiwa tersebut sangat beragam genrenya, mulai dari yang bersifat ilmiah hingga yang bersifat populer. Mulai dari yang berdasarkan data seratus persen hingga yang berdasarkan imajinasi semata. Keragaman tersebut diakomodir dalam pembelajaran sejarah. Untuk menjadikan pembelajaran sejarah ini lebih bermakna dan terarah (Andarwati, 2019), tentunya diperlukan metode menarik guna memancing minat para pembelajar dalam menyampaikan peristiwa (Pradana, 2017). 
Pembelajar dalam hal ini bukan hanya siswa atau para akademisi sejarah, pembelajar berarti semua orang yang mau belajar. Menurut Ausubel (Burhanudin, 20I4), belajar merupakan asimilasi bermakna. Oleh sebab itu, dapat disebutkan bahwa pembelajar dalam komunitas sejarah dan masyarakat sejarah merupakan para pembelajar yang mampu serta berminat memaknai peristiwa sejarah.

Berdasarkan hal tersebut, maka perlu sebuah wadah untuk mengapresiasi kemauan belajar para pembelajar sejarah. Salah satu wadah yang dapat digunakan adalah dengan pentigraf atau cerpen tiga paragraf. Menurut Indradi (2018a) pentigraf adalah kependekan dari cerpen tiga paragraf. Keringkasan dan kemenarikan cerita yang disajikan membuat pentigraf sebagai genre sastra yang sangat cocok untuk dipelajari pada era disrupsi ini (Saputra \& Meilasari, 2020a, 2020b). Ritzer (20I4) mengatakan bahwa sekarang kita sedang berada dalam Mc Donaldisasi masyarakat yang mengutamakan kecepatan serta keringkasan. Keringkasan tersebut juga berpengaruh pada bentuk karya sastra, salah satunya cerpen. Cerpen sebagai bagian dari karya sastra memuat sisi rekreatif dan edukatif lantaran selain terhibur, pembaca dapat mengambil nilai-nilai kehidupan yang diteladaninya sehari-hari (Listini \& Saraswati, 2017; Mujianto \& Pangesti, 2019; Susiana, 20I4). Salah satu strategi untuk menghibur adalah dengan mengubah bentuk cerpen menjadi pentigraf. Wujud pentigraf mampu mengakomodir keperluan ini, mulai dari penulis hingga pembaca akan diuntungkan melalui genre ini (Indradi, 2018b; Saputra \& Meilasari, 2020b). Penulis diuntungkan karena pentigraf ditulis dalam bentuk yang ringkas dan sederhana. Melalui gawai yang dimiliki, setiap orang bisa membuat pentigraf. Saat menunggu di bank, di halte, di sekolah, di rumah dan di setiap tempat maka pekerjaan ini dapat dilakukan. Pembaca pun juga diuntungkan, karena bagi pembaca yang kurang sabar pasti akan mencapai klimaksnya ketika membaca cerpen yang tidak terlalu panjang (Saputra \& Meilasari, 2020a; Yulisna, 2016). Pembaca yang seperti ini akan menganjurkan agar cerita disampaikan dalam bentuk tiga paragraf saja. Oleh sebab itu, pentigraf ini layak untuk disajikan sebagai salah satu alternatif dalam pembelajaaran sejarah di masyarakat.

Menurut Tjahjono (2017), pentigraf sebenarnya merupakan salah satu wujud dari flash fiction, yaitu prosa fiksi yang singkat, meskipun tidak ada ukuran baku terkait singkatnya itu. Pentigraf ini merupakan salah satu genre fiksi mini yang sempat melejit di tahun 1980 an. Salah satu pionirnya adalah Tengsoe Tjahjono, seorang sastrawan yang aktif mengirimkan pentigrafnya ke harian Suara Indonesia Malang (Indradi, 20I8b). Selain Tengsoe, tentu banyak juga sastrawan nasional yang menggeluti bidang ini. Sayangnya, bidang pentigraf ini sempat surut gaungnya di tahun 1990-an hingga awal abad 2I. Genregenre lain pun mulai bermunculan, sehingga mampu menenggelamkan genre unik ini. Kemunculan Pentigraf baru dirasakan belakangan ini setelah beberapa sastrawan nasional mulai turun gunung untuk menyadarkan budaya literasi, khususnya literasi sastra.

Tepatnya pada tahun 2015, Tengsoe mendirikan sebuah komunitas sastra virtual bertajuk Kampung Pentigraf Indonesia. Komunitas tersebut terdiri dari beragam latar belakang profesi. Satu hal yang menyatukanya adalah kecintaan terhadap sastra dan mau belajar sastra. Presiden Kampung Petigraf Indonesia adalah Dr. Tengsoe Tjahjono, sedangkan para pembuat pentigraf disebut sebagai pentigrafis (Saputra \& Meilasari, 2020b). Para pentigrafis mulanya menautkan cerpen tiga paragrafnya dalam jejaring sosial facebook. Masing-masing anggota saling mengomentari dan memberi masukan. Ide untuk menjadikan pentigraf sebagai buku pun mulai digagas. Buku pentigraf pertama dari komunitas ini berjudul dari Alea Menuju Robot Sempurna. Buku tersebut ternyata menjadi stimulus sekaligus triger bagi para pentigrafis untuk meresonansi budaya menulis pentigraf pada berbagai ranah. Salah satu wujud resonansinya adalah dengan membuat pentigraf sejarah di Komunitas Roode Burg Soerabaia.

Bentuk pentigraf memang terbatas hanya tiga paragraf, tapi semua unsur cerita tetap harus dihadirkan dalam sebuah pentigraf. Unsur tersebut adalah (I) tokoh, (2) latar, (3) alur, (4) tema, dan unsur intrinsik lainya. Menurut Budianta (dalam (Tjahjono, 2017), pentigraf secara tidak langsung mengajak pembaca untuk menyelami esensi terdalam sekaligus memeras satu kisah hingga tinggal saripatinya saja. Oleh sebab itu, pembaca akan mampu menghayati inti cerita dan genre ini sangat cocok bagi pembaca yang sibuk sekalipun. Herwanta (2018) mengatakan bahwa karya tulis seperti pentigraf 
merupakan karya sastra yang bisa menjadi sarana pewarta pesan sekaligus iman. Pendapat tersebut menunjukkan bahwa pentigraf dapat diterima oleh semua kalangan, termasuk kalangan pebelajar sejarah.

Pembelajaran sejarah dapat tersampaikan dengan tepat pada masyarakat apabila terdapat sebuah komunitas atau kelompok yang mau turun dan berperan aktif membelajarkannya. Salah satu komunitas tersebut adalah komunitas Roode Brug Soerabaia. Komunitas yang bermarkas di Surabaya ini sudah lama aktif mengedukasi masyarakat melalui kegiatan sejarah. Beragam kegiatan telah dilakukan seperti (I) parade juang, (2) bedah buku, (3) penelitian, (4) video dokumenter, (5) penyajian dokumen sejarah secara daring pada masyarakat. Salah satu inovasi yang ingin dilakukan oleh Komunitas Roode Burg Soerabaia adalah membelajarkan masyarakat menghayati cerita sejarah melalui sastra. Karya sastra merupakan cerminan dari realitas kehidupan masyarakat yang terekam melalui deretan cerita yang ditulis oleh pengarang (Setiawan \& Musaffak, 2019). Peristiwa sejarah merupakan realitas kehidupan masyarakat. Oleh sebab itu, pembuatan pentigraf sebagai sarana pembelajaran pada masyarakat ini disambut baik oleh Komunitas Roode Burg Soerabaia.

Penelitian terdahulu mengenai pentigraf dan komunitas Roode Burg Soerabaia adalah penelitian berjudul ...... yang dilakukan oleh Indradi (2018b) dosen Universitas Katolik Widya Karya Malang. Penelitian tersebut menghasilkan temuan yang menyimpulkan bahwa pembelajaran sastra di sekolah, khususnya menulis prosa fiksi, bukan lagi menjadi kendala bagi siswa. Penelitian berikutnya dilakukan oleh Pradana (2017), Guru MAN I Malang, berjudul Pengenalan Sejarah Lokal Berbasis Reenacment oleh Komunitas Roode Burg Soerabaia. Penelitian ini menghasilkan temuan bahwa pengenalan sejarah berbasis reenactment merupakan wujud nyata dari tindak lanjut memahami peristiwa sejarah. Bermain peran dalam bentuk drama adalah fokus yang dijadikan dalam penelitian ini. Berdasarkan dua penelitian tersebut, maka peneliti ingin menggabungkan teknik pembuatan pentigraf dengan apresiasi konten peristiwa atau kisah sejarah. Tujuan penelitian ini ada dua yaitu (I) mendeskripsikan strategi pembelajaran sejarah melalui pentigraf pada masyarakat dan (2) mendeskripsikan proses kreatif pembuatan buku pentigraf sejarah yang dilakukan oleh Komunitas Roode Burg Soerabaia.

\section{METODE}

Jenis penelitian ini adalah penelitian kualitatif. Menurut Edson (Sherman \& Webb, 2005) berpendapat bahwa penelitian kualitatif merupakan bentuk wacana moral untuk memahami masa menjadi pelaku utama dalam pengambilan serta pembuatan data. Data yang digunakan dalam penelitian ini adalah pentigraf sejarah yang diterbitkan oleh Komunitas Roode Burg Soerabaia. Teknik pengambilan data dalam penelitian ini ada tiga yaitu (I) observasi, (2) wawancara, dan (3) studi pustaka. Teknik analisis data dalam penelitian ini adalah analisis deskriptif. Dalam penelitian ini, peneliti juga terlibat aktif menginisiasi terbitnya pentigraf sejarah. Peneliti ikut dalam proses pelatihan, pembuatan, hingga peluncuran pentigraf sejarah. Validasi data diperoleh dengan cara triangulasi yaitu membaca buku referensi, observasi, dan wawancara dengan narasumber. Metode yang digunakan adalah metode observasi partisipatoris. Metode observasi partisipatoris merupakan metode penelitian kualitatif yang melibatkan peneliti untuk terjun sekaligus pembuatan pentigraf sejarah ini secara garis besar ada tiga, yaitu (I) pelatihan, (2) proses pembuatan, dan (3) peluncuran buku. Tiga tahap tersebut dilakukan oleh peneliti beserta kedua patner dari Roode Burg Soerabaia yaitu Ady Setiawan sebagai kurator dan Rintahani Johan Pradana sebagai editor. Penelitian ini juga melibatkan anggota Komunitas Roode Burg Soerabaia dalam penulisan antologi pentigraf sejarah.

\section{HASIL DAN PEMBAHASAN}

Hasil dan pembahasan dalam penelitian mengenai strategi pembelajaran pentigraf sejarah sebagaimana pada uraian berikut.

\section{Strategi Pembuatan Pentigraf}

Komunitas Rooden Burg (RB) Soerabaia merupakan sebuah komunitas yang diisi oleh para pecinta dan pemerhati sejarah dari segala bentuk profesi yang ada di Surabaya. Menurut Pradana (2017), 
komunitas RB merupakan wujud nyata merespons keberadaan situs dan sumber sejarah yang ada di Surabaya. Selama ini kegiatan yang dilaksanakan oleh RB sungguh inovatif dan kreatif. Mulai dari website, film dokumenter, hingga teatrikal. Melihat potensi yang sedemikian besar itu, maka pembuatan pentigraf sejarah dapat dimulai dari komunitas ini. RB sebagai pioner untuk membuat kitab pentigraf sejarah. Keberagaman anggota RB merupakan sebuah kekayaan tersendiri yang nantinya akan mewarnai kitab pentigraf ini. Memang tidak semua anggota RB suka menulis, tapi pentigraf merupakan wadah yang tepat bagi orang-orang yang tidak berprofesi sebagai penulis untuk berani menuangkan gagasan, ide, serta pengalamannya dalam bentuk karya.

Pertama, tahap pra pelatihan. Sebelum membuat buku, alangkah baiknya anggota Komunitas Roode Burg Soerabaia diberi pelatihan terlebih dahulu. Hal tersebut bertujuan untuk memberikan skemata awal tentang pentigraf, sekaligus pemaparan teknik menulis cerpen tiga paragraf pada peserta. Sebelum melakukan pelatihan, maka ada tiga orang dari Roode Burg Soerabaia membentuk tim kecil untuk mensukseskan kegiatan tersebut. Tim kecil itu terdiri dari (I) Ardi Wina Saputra, (2) Rintahani Johan Pradana, dan (3) Ady Setiawan. Nama pertama adalah peneliti sendiri, berikutnya adalah anggota Roode Burg Soerabaia sekaligus peneliti yang memfokuskan diri pada pendidikan sejarah, dan yang ketiga adalah ketua Komunitas Roode Burg Soerabaia. Kegiatan awal yang dilakukan adalah (I) mendiskusikan waktu dan tempat pelaksanaan pelatihan, (2) merumuskan materi yang diberikan pada peserta pelatihan, dan (3) membuat contoh pentigraf sejarah sebagai stimulus peserta.

Kedua, tahap pelatihan, tahap ini dikemas dalam wujud diskusi sekaligus praktik menulis di salah satu kafe di Surabaya. Pengemasan dibuat semenarik dan secair mungkin, agar ide-ide kreatif dari peserta pelatihan dapat muncul dengan sendirinya. Materi pelatihan ada dua sesi yaitu penyampaian teknik menulis pentigraf dan penyampaian konten sejarah sebagai wujud penulisan pentigraf. Setelah materi disampaikan, peserta diberi dua kertas. Kertas pertama berisi contoh pentigraf dan kertas kedua adalah kertas kosong yang dijadikan peralatan dalam menulis. Mulanya, banyak peserta yang merasa kesulitan dan ragu untuk mencoba, tapi tim yang telah dibentuk berusaha untuk terus meneguhkan peserta agar percaya diri dalam menulis. Tiga puluh menit kemudian, beberapa peserta sudah bisa menghasilkan satu pentigraf. Peserta yang mampu menghasilkan pentigraf diminta untuk membacakan pentigraf tersebut pada peserta lainnya. Hal ini ternyata mampu menarik minat peserta lainnya untuk segera menyelesaikan minimal satu pentigraf dalam pelatihan tersebut. Hampir seluruh peserta maju secara bergantian untuk membacakan pentigrafnya. Di akhir pelatihan, peserta diberi waktu sepuluh hari untuk menyelesaikan tiga pentigraf. Pentigraf yang sudah selesai dikumpulkan melalui surat elektronik tim pelatihan.

Ketiga, tahap kurasi, editing, dan pemberian ilustrasi. Pentigraf yang sudah dikumpulkan melalui surel, kemudian diunduh oleh kurator. Setelah itu kurator mendistribusikannya pada editor dan ilustrator. Editor melakukan proses editing dengan menjalin komunikasi pada kurator dan penulis. Di sisi lain, ilustrator sudah mulai mengerjakan ilustrasi pada beberapa cerpen yang dianggap perlu untuk diperkuat dengan gambar. Keempat, tahap penataan letak dan percetakan. Setelah semua pentigraf diedit dan beberapa pentigraf diberi ilustrasi, maka tahap selanjutnya adalah penataan dan percetakan. Tahap ini dilakukan oleh penerbit. Selain menata dan mencetak, penerbit juga mengurus ISBN dan menerbitkan sesuai dengan jumlah yang diinginkan pemesan. Setelah buku diterbitkan, langkah yang dilakukan adalah sosialisasi pada masyarakat. Sosialisasi dilakukan dengan cara bedah buku. Peserta yang menghadiri kegiatan bedah buku ini berasal dari berbagai kalangan. Pentigraf yang dihasilkan sangat cocok dibaca oleh semua umur dan dapat dibelajarkan pada semua kalangan. Beberapa peserta dalam kegiatan bedah buku ini ada yang berprofesi sebagai guru sehingga berniat untuk membelajarkan pentigraf pada peserta didiknya.

Berbagai media baik cetak maupun daring telah memuat berita tentang pentigraf sejarah ini. Jawa Pos dan Radar Surabaya merupakan dua media cetak yang terus menerus memberitakan pembuatan pentigraf ini. Beberapa pembaca juga mengapresiasi dalam wujud resensi yang ditautkan pada laman pribadinya. Buku ini juga disosialisasikan melalui youtube dan jejaring sosial seperti instagram, whats aps, facebook, line, twitter, dan berbagai instagram lain yang sesuai dengan selera generasi milenial. Hal ini 
bertujuan untuk memancing masyarakat khususnya generasi milenial untuk mau belajar dan memahami kisah sejarah, dengan demikian proses transformasi pengetahuan sejarah dapat terjadi melalui metode yang inovatif.

\section{Teknik Pentigraf}

Cerpen merupakan salah satu bagian dari karya sastra. Pada dasarnya karya sastra memerlukan proses kreatif dalam pembuatannya, termasuk pentigraf. Panjang pendek cerita bergantung pada kebutuhannya. Susiana (20I4) mengatakan bahwa panjang pendek cerpen bergantung pada keterbatasan unsur-unsurnya. Oleh sebab itu, dalam cerpen dikenal dengan unsur intrinsik dan unsur ekstrinsik. Dalam cerpen dikenal ada dua unsur utama yaitu unsur intrinsik dan unsur ekstrinsik. Unsur ekstrinsik merupakan unsur di luar karya sastra yang mencangkup sejarah hingga lingkungan yang membentuk karya sastra (Wellek, Warren, \& Budianta, I995). Unsur intrinsik merupakan unsur pembentuk karya sastra itu sendiri, seperti tokoh, plot, latar, dan lain sebagainya. Salah satu bagian terpenting dalam unsur intrinsik ini adalah Plot, bisa jadi plot dikatakan sebagai kerangka utama cerpen. Plot merupakan alur atau jalan cerita, terjadinya plot berasal dari sebuah konflik cerita (Atmowiloto, 2013).

Plot juga merupakan penentu struktur cerita, secara umum plot terbagi menjadi tiga bagian yaitu opening, inti, dan ending (Atmowiloto, 2013). Pembukaan harus ditulis semenarik mungkin untuk menarik minat baca, inti merupakan konflik utama dalam cerita. Ending merupakan akhir cerita atau penyelesaian dari konflik tersebut. Ending yang menarik adalah ending yang tidak dapat ditebak. Bahasa dalam cerpen bukanlah bahasa formal atau ilmiah, bukan juga bahasa yang terlalu berbunga-bunga sehingga tidak dapat dimengerti oleh pembaca. Shirazy (2008) mengatakan bahwa bahasa dalam menulis sastra baiknya adalah bahasa yang mampu mengajak dialog dengan pembaca. Hal tersebut telah dibuktikannya ketika melakukan proses kreatif berupa novel Ayat-ayat Cinta. Pengalaman dan gaya bahasa komunikatif yang dipilih oleh Habiburrahman El Shirazy dapat dijadikan rujukan dalam menulis cerpen.

Strategi cilukba merupakan strategi yang dicetuskan oleh sastrawan Indonesia masa kini, yaitu Ayu Utami. Dasar pembentukannya adalah teori kenikmatan rasa ingin tahu (Utami, 20I5). Kenikmatan ingin tahu ini terdapat dalam permainan cilukba. Ayu Utami mengonstruksi permainan tersebut sebagai strategi dalam menulis cerpen. Tiga struktur pokok dalam plot, dimodifikasi menjadi lebih menarik melalui strategi cilukba. Strategi ini telah diterapkan selama setahun terakhir oleh Ayu Utami dalam kelas sastra, komunitas sastra, dan berbagai workshop kepenulisan. Strategi cilukba memiliki kelebihan yaitu mampu membuat pembaca menjadi penasaran, sehingga mampu menarik minat baca. Strategi ini juga sangat cocok apabila diterapkan dalam menghadapi lomba-lomba penulisan cerpen. Hal ini karena dalam menilai cerpen, juri akan menilai pembuka cerpen dan akhir ceritanya saja. Apabila dua unsur tersebut menarik, maka juri barulah membaca keseluruhan. Hal ini berpengaruh terhadap efisiensi waktu penjurian. Kelemahan strategi cilukba adalah strategi ini hanya bisa diterapkan pada penulis yang memiliki kemampuan dalam bersastra. Bagi penulis pemula yang benar-benar awam akan kesulitan dalam mencerna maksud dari strategi ini.

Berdasarkan penuturan Ayu Utami dalam workshop menulis cerpen di Perpustakaan Kota Malang pada tahun 20I4. Strategi cilukba yang diterapkan ini mampu meningkatkan kemampuan menulis cerpen para peserta didiknya di komunitas Utan Kayu. Beberapa kelas pelatihan penulis privat yang diselenggarakannya baik secara individu maupun kelompok, juga mendapatkan hasil yang signifikan ketika berhasil menerapkan strategi cilukba. Hal tersebut membuktikan bahwa strategi cilukba memiliki pengaruh positif dalam proses kreatif menulis cerpen. Berdasarkan pertimbangan tersebutlah maka strategi cilukba dipilih sebagai strategi pembelajaran menulis pentigraf di masyarakat.

\section{Deskripsi Buku Pentigraf}

Penelitian ini menghasilkan sebuah buku pentigraf sejarah berjudul Ke Mana Perginya Para Perwita? Buku ini diterbitkan pada awal tahun 2018 oleh penerbit buku Litera Yogyakarta bekerjsasama 
dengan Komunitas Roode Brug Soerabaia. Terdapat 45 pentigraf yang ditulis oleh 22 anggota Roode Burg Soerabaia.

Empat puluh lima judul pentigraf tersebut antara lain (I) Di Tepi Kali Gunung Sari, (2) Arabelle, (3) William Ackerley, (4) Inferno, (5) Arisaka Kosong, (6) Ke Mana Perginya Para Perwira? (7) Senyuman Sahabat, (8) Ilusi Caping Gunung, (9) Gugurnya Sahabat, (I0) Goresan Bertinta Darah, (II) Menyambut Sukoco, (I2) Apa Maumu? (I3) Tresno Tenanan, (I4) Saksi Bisu, (I5) Pembebasan, (I6) Bukan Musuh, (17) Sajak Perang, (18) Masa Lalu, (19) Curhat, (20) Wangi Tanah Basah, (2I) Luka Penjaga, (22) William Temanku, (23) Bapak Hilang, (24) Arisakaku, (25) Jodohku Pilihanku, (26) Balada si Panjul, (27) Kasih Tak Sampai, (28) Aku Tak Suka Panggilan Itu, (29) Cerita di Balik Senjata, (30) Pengecut yang Terobek dari Ingatan, (3I) Detik, (32) Mereka Ikut Rapat, (33) Tangis, (34) Gadis Kembang Jepun, (35) Pemuda, (36) Stasiun Yang Terlupakan, (37) Mossel-Mossel Selatan Belanda, (38) Laskar di Ujung Pena, (39) Lamaran Aminah, (40) Jembatan Merah, (4I) Membidik Tentara Rhapsody, (42) Untuk Merah Putih, (43) Perangkap Jaman, (44) Berputar, (45) Aksi Gila.

Cerita-cerita yang dibuat dalam pentigraf sejarah ini bertema tentang perang I0 November yang terjadi di Surabaya dan sekitarnya. Tema ini sengaja dipilih karena sesuai dengan tujuan pembuatan pentigraf yaitu untuk mengenalkan peristiwa sejarah, khususnya peristiwa IO November pada masyarakat. Cerita yang dikisahkan pun juga bersifat fiksi dan fantasi. Menurut Andalas (2017) fantasi bukanlah cerita yang bertujuan sebagai hiburan semata, tetapi makna yang disematkan oleh pembacanya.

Meskipun bersifat fiksi dan fantasi, peneliti juga melakukan riset dalam pembuatannya. Data riset tersebut diperoleh ketika para penulis berproses bersama Komunitas Roode Burg Soerabaia. Skemata awal itulah yang dijadikan bekal dalam pembuatan cerita. Kisah-kisah yang diangkat pun juga kisah-kisah yang selama ini jarang diekspos atau dipublikasikan oleh media massa. Jawa Pos edisi I5 Februari 2018 menyoroti salah satu kisah unik yang ditulis dalam pentigraf sejarah ini. Kisah tersebut ditulis oleh Sinung, salah satu anggota Roode Burg Soerabaia. Pentigraf Sinung bercerita tentang kisah cinta suster ngesot dengan seorang pejuang bernama Cak Ihsan. Latar yang digunakan dalam cerita adalah rumah sakit yang saat ini menjadi pusat perbelanjaan di Surabaya. Sama sekali tidak ada kesan horor dalam tulisan ini, yang ada malah kisah mengharukan sehingga pembaca tertarik untuk menelusuri kisah dan latar tersebut. Satu kisah sudah mampu membuat pembaca untuk penasaran dan berkeinginan mempelajari peristiwa sejarah lebih dalam lagi, kisah yang lainnya pun juga tidak kalah menarik. Ady Setyawan memiliki standard dan kualifikasi tinggi dalam mengkurasi cerita. Meskipun demikian, Ady tidak serta merta membuang atau memotong naskah yang tidak sesuai dengan ketentuan yang telah diberikan. Dia memberikan pendampingan pada para penulis, sehingga karya yang dihasilkan oleh para penulis benar-benar berkualitas.

Dua puluh dua penulis dalam buku tersebut adalah (I) Ardi Wina Saputra, (2) Rintahani Johan Pradana, (3) Ady Setiawan, (4) Anggun Esti Wardani, (5) Danti Ayu Irawati, (6) Tri Prastyo Aji, (7) Indra Eka Saputra, (8) Ari Ganesa, (9) Sinung Widiyanto, (I0) Rahadyan Putra Biguna, (II) Satrio Sudarso, (I2) Rahmad Aryo Widodo, (I3) Arief Yanuar, (I4) Lawrence Eka, (I5) Ayu Saraswati, (I6) Liem Kim Haw, (17) Agustina Elisabet, (I8) Kurnia Sari Widodo, (19) Titta Santya, (20) Hari Sasongko, (2I) Baiq Tamara Febriliandina Rizqy, (22) Rizki Aminulloh Santoso. Para penulis pentigraf ini berasal dari latar belakang pendidikan yang beragam, sehingga skemata literasinya pun juga beragam. Salah satu contohnya adalah Liem Kim Haw atau biasa dipanggil dengan sebutan Gepeng. Dia mengaku pada Peneliti bahwa ini adalah pengalaman pertamanya dalam menulis secara profesional. Terakhir dia menulis sastra ketika dia duduk di bangku sekolah, sudah puluhan tahun tidak menulis sastra. Bentuk pentigraf yang ringkas dan sederhana membuatnya percaya diri dalam menulis. Hasilnya, dia mampu membuat pentigraf sejarah berjudul Gugurnya Sahabat dan dibukukan dalam antologi kumcer pentigraf ini. 


\section{Contoh Pentigraf}

Berikut adalah contoh pentigraf yang dimuat dalam buku Ke Mana Perginya Para Perwira? berjudul Menyambut Sukoco.

\section{Menyambut Sukoco}

Hari ini adalah hari yang paling kutunggu-tunggu. Gencatan senjata serta perundingan damai telah didengungkan di berbagai radio. Para laskar pasti pulang kembali ke kotanya masing-masing, begitu juga dengan Sukoco anakku. Ah aku ingin melihat betapa gagahnya ia sesampainya di rumah. Kami, para ibu dan lansia yang tinggal di kampung Bandulan Kota Malang sudah tak sabar lagi melihat kepulangan anak-anak kami yang berangkat ke Surabaya, sejak bulan November silam.

Bunyi sirine tiba-tiba mengagetkanku, orang-orang kampung beranjak lari keluar ke arah balai desa. Kedatangan mereka akan di sambut di balai desa terlebih dahulu. Pasti itu para tentara laskar sudah datang, batinku berbisik. Hatiku berdebar kencang, kulangkahkan kaki ini sekuat tenaga. Hingga sampailah di depan kerumunan yang memenuhi balai desa.

Suara riuh bercampur gaduh ada senyum juga tangis yang terisak. Semuanya berbaur menjadi satu. Peluk dan cium silih berganti, aroma keringat dan debu berbagi lagi. Kulihat ada seorang bocah mungil duduk di bawah tiang bendera. "Sukoco!" Aku berlari ke arah tiang itu, lalu kupeluk teramat erat. Sangat erat. Tiba tiba, tiga lelaki mendatangiku. Menyeretku dari tiang bendera itu. "Nyebut Mbok Nah! Sameyan Nyebut Asmane Gusti Allah! Masak setiap kali ada tentara pulang, sameyan selalu meraung raung di tiang bendera itul!" tak kupedulikan perkataan para lelaki itu. Mereka menyeretku lalu membopongku ke tempat yang jauh dari tiang bendera. Kulihat Sukoco masih duduk di bawah tiang bendera, meski ku tahu hanya aku saja yang bisa melihat kepulanganya.

Pentigraf tersebut bercerita tentang seorang ibu yang menanti kepulangan anaknya dari peperangan. Tokoh utama adalah seorang ibu dan tokoh sampingan adalah tiga pemuda yang mengangkutnya. Latar tempat di Kota Malang, latar waktunya pagi, dan latar suasana miris. Peristiwa yang diangkat adalah kepulangan para laskar ke daerah asalnya setelah perang IO November selesai. Strategi Cilukba digunakan dalam penulisan cerpen ini. $C_{i} i$ menceritakan tentang seorang ibu yang menantikan hari kepulangan anaknya. Tokoh utama dan latar diperkenalkan dalam paragraf pertama ini. Selanjutnya adalah Luk, pada tahap ini konflik batin yang mendebarkan dimulai. Gejolak batin seorang ibu menantikan kehadiran anaknya mulai terasa. Tahap terakhir adalah $B a$, ternyata ibu tersebut hanya mampu melihat bayangan anaknya saja padahal anaknya sudah tiada. Tahap ini merupakan tahap klimaks yang menjadi penutup dalam cerita. Oleh sebab itu, penutup yang tidak terduga perlu disiasati oleh penulis agar cerita yang dibuat memiliki klimaks yang memuncak. Semakin memuncak klimaksnya, maka pembaca akan semakin terkesan, sehingga berencana untuk membaca cerita yang ditulis oleh penulis yang sama atau menghabiskan seluruh kisah yang terdapat dalam buku tersebut.

\section{SIMPULAN}

Era disrupsi merupakan sebuah era yang terjadi karena perkembangan teknologi informasi semakin berkembang. Disrupsi telah merambah pada segala aspek kehidupan, termasuk pendidikan. Saat ini pendidikan sudah mengarah pada model 4.0. Pembelajar serta masyarakat membutuhkan inovasi dalam menyerap pengetahuan. Proses tersebut dapat terjadi apabila dilakukan inovasi. Materi pembelajaran yang notabene membosankan seperti halnya sejarah harus mendapat perhatian lebih, khususnya dalam hal inovasi pembelajaran. Salah satu inovasi yang dilakukan adalah menggabungkan lintas disiplin ilmu yaitu sejarah dan sastra. Hal ini sesuai dengan strategi yang digunakan untuk menghadapi pendidikan 4.0 yaitu kolaborasi. Penggabungan sejarah dan sastra dalam rangka mengedukasi masyarakat untuk semakin memahami sejarah, dilakukan oleh Komunitas Roode Burg Soerabaia. Wujudnya adalah pembuatan pentigraf sejarah. Ada tiga tahap utama dalam pembuatannya yaitu (I) pelatihan, (2) pembuatan, (3) penerbitan. Ketiga tahap tersebut dikerjakan oleh anggota Komunitas Roode Burg Soerabaia dan dikuratori oleh Ady Setyawan, serta dieditori oleh Rintahani Johan Pradana. 
Hasil dari proses tersebut adalah pentigraf sejarah bertajuk Ke Mana Perginya Para Perwira? Terdapat 45 pentigraf dalam buku ini yang ditulis oleh 22 anggota Roode Burg Soerabaia. Teknik yang digunakan dalam menu Proses diseminasi dari pentigraf ini melalui media massa cetak maupun tulis, jejaring sosial, dan bedah buku. Diharapkan pentigraf ini mampu menjadi stimulus sekaligus triger bagi masyarakat untuk mau mengapresiasi peristiwa sejarah, khususnya melalui sastra.

\section{UCAPAN TERIMA KASIH}

Penulis mengucapkan terima kasih kepada Komunitas Roodeburg Soerabaia yang telah memberikan dukungan dalam penelitian ini. Penulis juga mengucapkan terima kasih kepada LP3M Universitas Katolik Widya Mandala Surabaya Kampus Madiun dan semua pihak yang telah berkontribusi dalam penelitian ini, sehingga penelitian ini dapat terlaksana dan diselesaikan dengan baik.

\section{DAFTAR PUSTAKA}

Andalas, E. F. (2017). Eskapisme realitas dalam dualisme Dunia Alice telaah psikologi sastra film Alice in Wonderland (2010). KEMBARA: Jurnal Keilmuan Bahasa, Sastra, dan Pengajarannya, 3(2), I85-195. doi: https://doi.org/I0.22219/kembara.v3i2.5I36

Andarwati, M. (2019). Pembelajaran sejarah kontekstual, kreatif, menyenangkan di kelas dengan "power director" bagi generasi Z. Jumnal Pendidikan Sejarah Indonesia, 2(I), 64-8I. doi: http://dx.doi.org/I0.I7977/um033v2iI2019p064

Atencio, M., Tan, Y. S. M., Ho, S., \& Ching, C. T. (20I5). 'The strawberry generation... they are too pampered' Pre-service physical education teachers' perspectives on outdoor education in Singapore. European Physical Education Review, 2I(I), 3I-50. doi: https://doi.org/I0.I177/I356336XI4550939

Atmowiloto, A. (2013). Mengarang itu gampang. Jakarta: Gramedia Pustaka Utama.

Bakti, C. P., \& Safitri, N. E. (2017). Peran bimbingan dan konseling untuk menghadapi generasi Z dalam perspektif bimbingan dan konseling perkembangan. Jurnal Konseling Gusjigang, 3(I), I04-I I3. doi: https://doi.org/I0.24I76/jkg.v3iI.I602

Burhanudin, J. (20I4). The dutch colonial policy on Islam: Reading the intellectual journey of snouck hurgronje. Al-Jami'ah: Journal of Islamic Studies, 52(I), 25-58. doi: https://doi.org/I0.I442I/ajis.2014.521.25-58

Fachrudin, M. U. (2016). Pengembangan modul sejarah M. Nitisemito dalam pembelajaran sejarah pergerakan nasional indonesia di SMA Negeri I Bae Kudus tahun ajaran 2016/20I7. (Doctoral Disertation not Publish), Universitas Negeri Semarang, Semarang.

Faqihuddin, A. (20I7). Internalisasi nilai-nilai humanistik religius pada generasi $Z$ dengan "design for change". Edukasia: Jurnal Penelitian Pendidikan Islam, I2(2), 263-284. doi: http://dx.doi.org/I0.2I043/edukasia.vI2i2.247I

Hardiana, Y. (20I7). Pembelajaran sejarah Indonesia berbasis peristiwa-peristiwa lokal di Tasikmalaya untuk meningkatkan kemampuan berpikir kritis. Historia: Jurnal Pendidik dan Peneliti Sejarah, I(I), 4I-46. doi: https://doi.org/IO.I7509/historia.vIiI.7008

Helaluddin, H., Tulak, H., \& Rante, S. V. N. (2019). Strategi pembelajaran bahasa bagi generasi Z: Sebuah tinjauan sistematis. Jurnal Pendidikan Edutama, 6(2), 3I-46. doi: http://dx.doi.org/10.30734/jpe.v6i2.499

Herwanta, A. (2018). Surga untuk pohon ulin dan cerita-cerita lainnya. Sidoarjo: Penerbit Buku Delima. Indradi, A. (2018a). Kitab pentigraf penjaja kopi tengah hari. Mojokerto: Temalitera.

Indradi, A. (2018b). Pentigraf sebagai penyambung benang putus dalam pembelajaran sastra. Paper presented at the Proceding Senabasa, Malang

Ishak, S., Omar, A. R. C., Al Bakri, F. M., \& Osman, L. H. (2018). Amalan pembelajaran dan kesannya terhadap pembentukan pengetahuan serta kemahiran perniagaan dalam kalangan Generasi Z (Learning practices and effect on the knowledge and skills development among $Z$ generation). 
Geografia-Malaysian Journal of Society and Space, I4(I), I5-28. doi: https://doi.org/I0.17576/geo-2018-I40I-02

Kasali, R. (2017). Strawberry generation, anak-anak kita berhak keluar dari perangkap yang bisa membuat mereka rapuh. Bandung: Penerbit Mizan.

Kristiawan, M., \& Rahmat, N. (2018). Peningkatan profesionalisme guru melalui inovasi pembelajaran. Jurnal Iqra': Kajian Ilmu Pendidikan, 3(2), 373-390. doi: https://doi.org/I0.252I7/ji.v3i2.348

Listini, L., \& Saraswati, S. (2017). Meningkatkan kemampuan menulis cerpen melalui model pembelajaran sinektik siswa kelas VII SMP Sandika Sukajadi. Jurnal Bindo Sastra, I(I), 24-27. doi: https://doi.org/I0.32502/jbs.vIiI.664

Lubis, A. H., \& Dasopang, M. D. (2020). Pengembangan buku cerita bergambar berbasis augmented reality untuk mengakomodasi generasi Z. Jurnal Pendidikan: Teori, Penelitian, dan Pengembangan, 5(6), 780-79I. doi: http://dx.doi.org/I0.17977/jptpp.v5i6.13613

Lubis, I. R., \& Ikhsan, J. (2015). Pengembangan media pembelajaran kimia berbasis android untuk meningkatkan motivasi belajar dan prestasi kognitif peserta didik SMA. Jurnal Inovasi Pendidikan IPA, I(2), I9I-20I. doi: https:// doi.org/I0.2I83I/jipi.vIi2.7504

Maskurin, S. (2019). Inspirasi dari kawasan bersejarah: Mengenalkan jejak peninggalan kolonial di Kota Delta untuk generasi Z. Jurnal Pendidikan Sejarah Indonesia, 2(I), 24-37. doi: http://dx.doi.org/I0.17977/um033v2iI2019p024

Mujianto, G., \& Pangesti, F. (2019). Penerapan model sinektik berbantuan LKPD dalam pembelajaran menulis cerpen kelas IX Mts. Muhammadiyah I Malang. KEMBARA: Jurnal Keilmuan Bahasa, Sastra, dan Pengajarannya, 5(2), I82-I94. doi: https://doi.org/I0.22219/KEMBARA.Vo15.No2.182-I94

Permatasari, E. A. (20I4). Implementasi pendekatan saintifik dalam kurikulum 2013 pada pembelajaran sejarah. Indonesian Joumal of History Education, 3(I), II-I6. Retrieved from https://journal.unnes.ac.id/sju/index.php/ijhe/article/view/3884

Pradana, R. J. (2017). Pembelajaran sejarah lokal berbasis re-enactment dalam komunitas penggiat sejarah Roodebrug Soerabaia. Sejarah dan Budaya: Jurnal Sejarah, Budaya, dan Pengajarannya, II(I), 7 I78. Retrieved from: http://journal2.um.ac.id/index.php/sejarah-danbudaya/article/view/I5I2/807

Purnomo, A., Ratnawati, N., \& Aristin, N. F. (2017). Pengembangan pembelajaran blended learning pada generasi z. Jurnal Teori dan Praksis Pembelajaran IPS, I(I), 70-76. doi: http://dx.doi.org/I0.I7977/um022vIiI2016p070

Rahayu, W. (2019). Pembelajaran sejarah untuk generasi z. Jumal Pendidikan Sejarah Indonesia, 2(I), I-7. doi: http://dx.doi.org/I0.I7977/um033v2iI2019p00I

Ritzer, G. (2014). McDonaldisasi masyarakat. Yogyakarta: Pustaka Pelajar.

Saputra, A. W., \& Meilasari, P. (2020a). Eksistensi komunitas kampung pentigraf sebagai komunitas cyber sastra di Indonesia. Paper presented at the Prosiding Seminar Nasional Bahasa dan Sastra Indonesia (SENASBASA), Malang.

Saputra, A. W., \& Meilasari, P. (2020b). Resonansi kampung pentigraf sebagai komunitas sastra 4.0 Indonesia. Jurnal Ilmiah FONEMA: Jurnal Edukasi Bahasa dan Sastra Indonesia, 3(2), 82-98. doi: http://dx.doi.org/I0.25I39/fn.v3i2.2785

Saryono, D. (2018). Pembelajaran sastra Indonesia pada era distupsi. Paper presented at the Konferensi Bahasa dan Sastra III, Malang

Setiawan, A., \& Musaffak, M. (2019). Eksistensi mistisisme dalam novel Amba karya Laksmi Pamuntjak KEMBARA: Jurnal Keilmuan Bahasa, Sastra, dan Pengajarannya (e-Journal), 5(2), I46-I56. doi: https://doi.org/I0.22219/kembara.v5i2.9672

Sherman, R. R., \& Webb, R. B. (2005). Qualitative research in education: Focus and methods. London and New York: UK Routledge Falmer. 
Shirazy, H. E. (2008). Bahasa \& sastra dalam berbagai perspektif. In A. Efendi (Ed.), Tentang menulis karya sastra: Yang dicintai pembaca, yang menggugah minat baca. Yogyakarta: Tiara Wacana.

Singh, A. (20I4). Challenges and issues of generation Z. IOSR Journal of Business and Management, I6(7), 59-63. Retrieved from: https://pdfs.semanticscholar.org/b 109/73a5c6dI If37542adc34455bb0c7fbcbbb9d.pdf

Susiana, S. (20I4). Peningkatan Kemampuan Menulis Cerpen dengan Media Videoklip pada Siswa Kelas IX F SMP Neger 2 Kalitidu Bojonegoro. EDU-KATA, I(2), III-II8. Retrieved from: http:// e-jurnal.unisda.ac.id/index.php/kata/article/view/278/III

Tapscott, D., \& Barry, B. (2009). Grown up digital: How the net generation is changing your world. London: McGraw-Hill New York.

Tjahjono, T. (2017). Pedagang jambu biji dari Phnom Penh dan cerita-cerita lainnya. Jakarta: Kosa Kata Kita.

Utami, A. (2015). Menulis dan berpikir kreatif. Jakarta: Kepustakaan Populer Gramedia.

Wellek, R., Warren, A., \& Budianta, M. (I995). Teori kesusastraan (terjemahan). Jakarta: Gramedia.

Yemima, K., \& Stefani, S. (2019). Khotbah eksposisi narasi yang kreatif dan kontekstual bagi anak-anak generasi z usia 5-6 tahun. Jurnal Gamaliel: Teologi Praktika, I(2), 72-85. doi: https://doi.org/I0.38052/gamaliel.vIi2.4I

Youarti, I. E., \& Hidayah, N. (2018). Perilaku phubbing sebagai karakter remaja generasi Z. Jurnal Fokus Konseling, 4(I), I43-I52. doi: https:/ / doi.org/I0.26638/jfk.553.2099

Yulisna, R. (2016). Kontribusi kemampuan memahami cerpen terhadap keterampilan menulis cerpen siswa kelas XI SMA Negeri 4 Padang. Jurnal Gramatika, 2(2), 72-83. doi: https://doi.org/I0.22202/ig.2016.v2i2.IIOI 